\title{
A 4-Year Survival Rate after Cardiac Pacing in A-V Block in the Heart Institute of Japan
}

\author{
Masayoshi Yokoyama, M.D., Masahiro Endo, M.D., \\ Moriei SekIGuchi, M.D., and Motokazu Hori, M.D.
}

\begin{abstract}
SUMmaRY
The long-term prognosis after cardiac pacing in A-V block was assessed by a follow-up study of 59 patients in whom pacing had been introduced 4 years or more before analysis. The 1 year survival rate was $85 \%$ and the 4 year survival rate was $71 \%$. These figures are substantially better than the survival rate reported in patients not paced. The mortality has been higher in patients older than 70 years old. Even though patients were reviewed monthly or every 3 months in a pacemaker clinic, there were 3 sudden deaths in 4 years.
\end{abstract}

\section{Additional Indexing Words :}

Pacemaker implantation Cardiac pacing Long-term prognosis of cardiac pacing

TN the past decade implantation of permanent pacemakers has become 1 established as the standard means of treating symptomatic complete heart block. The prognosis for patients with complete heart block associated with Adams-Stokes attacks has improved with this procedure. To date, however, there is little information on the long-term prognosis after cardiac pacing.

Fifty-nine of the 164 patients who had been treated with implantable pacemakers in our hospital had been paced 4 years or more before this study. These 59 patients were checked up in this study, and the 4-year survival rate after cardiac pacing in A-V block was analysed. 'The causes of death were also examined.

\section{Materials and Methods}

Between December 1967 and February 1971, 59 patients were subjected to long-tcrm pacing. All the patients had been paced for 4 years or more before the end of February 1975. There were 34 men and 25 women. The age distribution is shown in Fig. 1, ranging from 1 to 83 years, averaging in 50.2 years. All the cases had complete atrioventricular block, either continuously present, or occurring in recurrent fashion.

Form the Heart Institute of Japan, Tokyo Women's Medical College, 10 Kawadacho, Shinjukuku, Tokyo, Japan.

Received for publication May 16, 1975. 


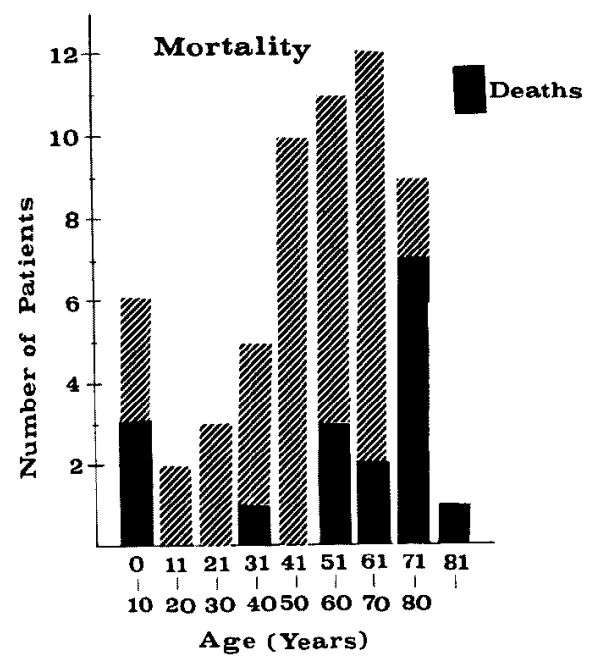

Fig. 1. Age distribution and mortality.

The indications for long-term cardiac pacing were Adams-Stokes attacks or near syncopal episodes in 51 patients, congestive cardiac failure with A-V block in 4 patients, frequent ventricular premature beat with $\mathrm{A}-\mathrm{V}$ block in 2 patients, Mobitz type 2 block without any symptoms in 1 patient and postoperative $A-V$ block without an episode of Adams-Stokes attack in 1 patient.

The etiology of the block is listed in Table I. Patients with coronary scler-

Table I. Etiology of Block

\begin{tabular}{lc}
\hline Idiopathic & 43 cases \\
Cardiomyopathy & 7 cases \\
Surgical & 6 cases \\
Postmyocardial Infarction & 2 cases \\
Congenital & 1 case \\
\hline
\end{tabular}

osis were included in the idiopathic group. Two cases with myocardial infarction were started permanent pacing not in acute but in chronic stage. A total of 123 pulse generators were implanted in 59 patients in 4 years, comprising 74 Medtronics, 32 Telectronics, 10 Devices, and other 7 units.

Pacing was usually performed by transvenous catheter electrode. Epicardial leads were implanted in young patients and in those who had experienced persistently transvenous pacing failure. Of the present 59 cases, 49 were endocardial and 10 were epicardial pacing.

The endocardial lead was inserted, in preference, into a cephalic vein in the deltopectoral groove or the external jugular vein. The tip of the lead was positioned under fluoroscopic control in the right ventricular apex. The final position was chosen to give a stimulation threshold of less than 1 milliampere, measured by Medtronic Model 5880 A. The generator was implanted in a subcutaneous pocket 


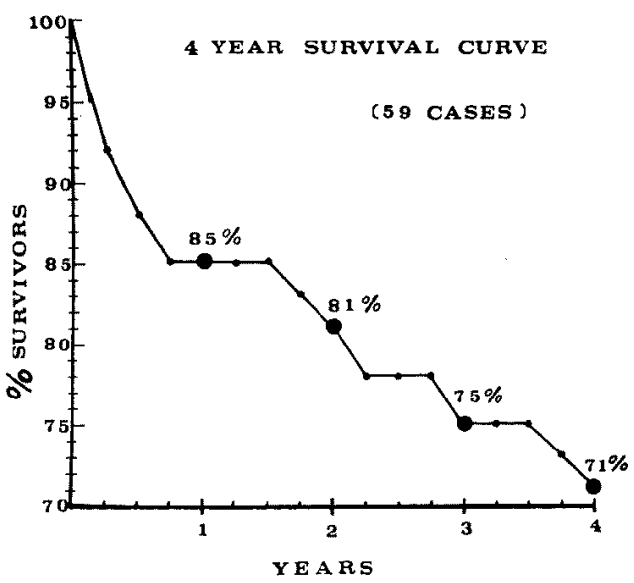

Fig. 2. Four-year survival curve.

at the anterior upper chest wall.

Patients were reviewed at 1-monthly intervals during the first 3 months, and at 3-monthly intervals up to 2 years after implantation and thereafter again at 1 monthly intervals, with clinical, electrocardiographic, and X-ray examination, as well as analysis of the pacing artefact on a rapid sweep oscilloscope. No cases were lost to follow up. All 59 patients had passed 4 years or more following the initial pacemaker implant. The survival of these patients was checked every 3 months up to 4 years to draw the 4 -year survival curve. The percentage indicated the number of surviving patients divided by 59 .

\section{Results}

Seventeen of the 59 patients died during 4 years, including 11 men and 6 women. The average age at death was 55.5 years. The majority of deaths occurred within the first year. The 4-year survival curve was shown in Fig. 2.

The one-year survival rate was $85 \%$, the 2 -year survival rate was $81 \%$, the 3 -year survival rate was $75 \%$, and the 4-year survival rate was $71 \%$. Nine of the 17 deaths occurred in the first 7 months following the pacemaker implantation.

The causes of death are shown in Table II. Eight of the 17 deaths underwent autopsy. There were 9 patients who died of non-cardiac causes. The remaining 8 patients died of cardiac diseases or of pacemaker failure. It can be seen that the death of Case 7 (Table II) was attributable to a pacemaker runaway. She lost consciousness suddenly at home about 10 months following the pacemaker re-implantation and referred to hospital by an ambulance. ECG revealed no patient's heart beats, but only pacing spikes 
Table II. Causes of Death and Their Survival Time Following Pacing

\begin{tabular}{|c|c|c|c|c|c|c|}
\hline & \multicolumn{2}{|c|}{ Cases } & $\begin{array}{c}\text { Age } \\
\text { (years) }\end{array}$ & Sex & Causes of Death & $\begin{array}{l}\text { Survival Time after } \\
\text { Pacing (months) }\end{array}$ \\
\hline \multirow{9}{*}{ 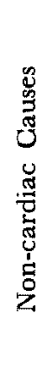 } & Case & 20 & 1 & $\mathrm{~F}$ & Acute pneumonia & 1 \\
\hline & Case & 48 & 7 & M & Serum hepatitis & 1 \\
\hline & Case & 46 & 75 & $\mathrm{M}$ & Uremia & 2 \\
\hline & Case & 15 & 74 & $\mathrm{~F}$ & Abdominal aneurysm & 4 \\
\hline & Case & 50 & 83 & $\mathbf{M}$ & Sigmoid cancer & 5 \\
\hline & Case & 43 & 51 & $\mathbf{M}$ & Pneumonia & 6 \\
\hline & Case & 16 & 66 & M & Intracranial hemorrhage & 27 \\
\hline & Case & 26 & 72 & M & Intracranial hemorrhage & 36 \\
\hline & Case & 2 & 78 & $\mathbf{M}$ & Senility & 48 \\
\hline \multirow{8}{*}{ 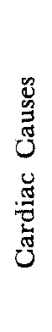 } & Case & 8 & 74 & $\mathbf{M}$ & Myocardial infarction & 1 \\
\hline & Case & 18 & 71 & M & Sudden death at home & 2 \\
\hline & Case & 31 & 77 & M & Cardiac failure & 7 \\
\hline & Case & 49 & 61 & $\mathrm{~F}$ & Cardiac failure & 20 \\
\hline & Case & 27 & 6 & $\mathrm{~F}$ & Arrhythmias & 24 \\
\hline & Case & 7 & 55 & $\mathrm{~F}$ & Pacemaker runaway & 25 \\
\hline & Case & 4 & 39 & F & Sudden death at home & 36 \\
\hline & Case & 58 & 53 & M & Cardiac failure & 44 \\
\hline
\end{tabular}

at the rate of $950 / \mathrm{min}$.

Cases 4 and 18 died suddenly and unexpectedly at home. Their causes of death were considered to be related to pacing failure in this paper in order to assure that no deaths due to pacing failure were missed. In all the remaining patients who died, the causes of death were known. Thus, 3 of the 17 deaths $(18 \%)$ were regarded as pacing-related.

The deaths in relation to the age group of the patients paced are shown in Fig. 1. While the number of patient are too small to allow statistical analysis, the anticipated higher mortality in groups over 70 years old is noted. Eight of 10 patients over 70 years old died in 4 years following the implant.

Long-term survival of 4 patients who had clinical evidence of chronic congestive heart failure without a history of Adams-Stokes attacks prior to pacemaker implantation, was examined. One (Case 49) of the 4 patients died at 20 months after pacemaker insertion because of the long-standing heart failure. In another case, congestive heart failure almost disappeared after pacing without any drugs administered to control failure. The remaining 2 cases still had congestive heart failure with digitalis and diuretic preparations.

The endocardial electrode catheter was used in 49 of the 59 cases, 14 of whom died in the 4 years. The epicardial electrode catheter was employed 
in the remaining 10 cases, 3 of whom died in the observation period. Therefore, no significant difference of mortality between endocardial and epicardial groups was noted in our series, though it was generally reported that endocardial leads were less hazardous.

\section{Discussion}

The natural history of complete heart block is not completely known. However, it seems clear from several reports ${ }^{1,2}$, that the 1-year survival rate for patients not paced is approximately $50 \%$ and the 5 -year survival rate is unlikely to be much more than $35 \%$. In our series, there is a 1-year survival of $85 \%$ and a 4 -year survival of $71 \%$, which are substantially better than the survival rate reported in patients not paced.

The quality of life permitted by pacemakers has generally been improved among the survivors, as has been lucidly described by Hori et al. ${ }^{3)}$

Legergren et al $^{11}$ reported a $16 \%$ mortality among 305 paced patients, practically all the deaths occurring within the first year. They compared this with a first year mortality of $48.5 \%$ in 204 patients treated medically. The high mortality rates in the first year for paced cases are remarkably similar in most published series ${ }^{4-7)}$ as in our series.

Chardack et $\mathrm{al}^{77}$ showed a 1-year survival of approximately $80 \%, 2$-year survival of $78 \%$, and a 5 -year survival of $50 \%$.

In McDonald's series, ${ }^{8}$ ) a 1-year mortality after the permanent pacing was only $6.8 \%$, but their patients as materials seemed to be healthier compared to ours, because 6 of our 9 deaths in the first year were attributable to non-cardiac causes as shown in Table I. Six deaths per se would present $10 \%$ mortality in our series. It is evident that mortality rates or survival rates are considerably influenced by general conditions of paced patients. It would be more reasonable approach on considering the prognosis of paced patients to describe the number of possible pacing related deaths. From this point of view, only $3(18 \%)$ of the 17 deaths were regarded as possible pacing related in 4 years in ours, while Zion et $\mathrm{al}^{9)}$ mentioned $40 \%$ of their deaths were pacing related.

It has been emphasized ${ }^{6,9)}$ that pacing related deaths were considerably diminished with the institution of a special clinic for follow up of patients. Our pacemaker clinic was also rewarded by a significant decrease in emergency complications, but still 3 sudden deaths were unfortunately encountered in the present series. The pacing of those 3 cases was completely satisfactory in the pacemaker clinic prior to their sudden deaths.

Out of the 17 deaths, 14 which were not pacing related might have also 
died even with the use of ideal implantable pacemakers. Therefore based on our patients, the use of ideal pacemakers in the future would increase the 4-year survival rate from the present $71 \%(42 / 59)$ to $76 \%(45 / 59)$.

In the Bernstein's report ${ }^{6)}$ from Canada, pulmonary emboli were found in 9 of the 22 patients who died in the first year after pacing. In our series, however, no pulmonary emboli were experienced, even though 8 of the 17 deaths underwent autopsy. As similar pacemaker electrodes were employed in both hospitals, this significant difference of pulmonary emboli between Canada and Japan is extremely interesting.

Another considerable difference of complications between the 2 nations is concerning the myocardial perforation by the pacemaker electrode. Our 49 cases with the endocardial electrode catheter showed no perforation in 4 years, whereas it occurred in $8(7.1 \%)$ of their 97 cases with the electrode catheter. ${ }^{6}$

\section{REFERENCES}

1. Johansson BW: Adams-Stokes syndrome. A review and follow up study of forty-two cases. Am J Cardiol 8: 76, 1961

2. Friedberg GK, Donoso E, Stein WG: Nonsurgical acquired heart block. Ann New York Acad Sci 111: 835,1964

3. Hori M, Hashiba K, Hosoda S, Kimura E: Analysis of current status of long-term cardiac pacing in Japan. Proceedings of the IVth International Symposium on Cardiac Pacing, Groningen, 1973

4. Lagergren $H$, Johansson L, Schueller $H$, Kugelberg J, Bojs G, Alestig K, Linder E, Borst HG, Schaudig A, Giebel O, Harms H, Redewald G, Scheppokat KD: 305 cases of permanent intravenous pacemaker treatment for Adams-Stokes syndrome. Surgery 59: 494 1966

5. Goldstein S, Moss AJ, River RJ, Jr, Weiner RS: Transthoracic and transvenous pacemakers. Brit Heart J 32: 35, 1970

6. Bernstein V, Rotem GE, Peretz DI: Permanent pacemakers: 8-year follow-up study. Ann Int Med 74: 361, 1971

7. Chardack WM, Gage AA, Federico AJ, Schimert G, Greatbatch W: Five years clinical experience with an implantable pacemaker: An appraisal. Surgery 58: 915, 1965

8. McDonald A, Layton C: Four years experience of cardiac pacemaking with the Devices asynchronous generator. Brit Heart J 35: 1041, 1973

9. Zion MM, Marchand PE, Obel IWP: Long-term prognosis after cardiac pacing in atrioventricular block. Brit Heart J 35: 359, 1973 